\begin{tabular}{ccc}
\hline & International Journal of Engineering \& Technology, $7(3.4)(2018) 122-126$ \\
SPC & Website: www.sciencepubco.com/index.php/IJET \\
Research paper & Technology \\
\hline
\end{tabular}

\title{
Automatic Door Control System Using SMS Gateway Base on Ar- duino Uno and Ultrasonic Sensor
}

\author{
Adam Faroqi $^{1}{ }^{*}$, Adi Fitriadi ${ }^{1}$, Neni Utami Adiningsih ${ }^{1}$, Muhammad Ali Ramdhani ${ }^{2}$ \\ ${ }^{1}$ Department of Electrical Engineering, UIN SunanGunungDjati Bandung, Indonesia \\ ${ }^{2}$ Department of Informatics, UIN SunanGunungDjati Bandung, Indonesia \\ *Corresponding author E-mail:adam.faroqi@uinsgd.ac.id
}

\begin{abstract}
The purpose of this research is to design an automatic door control system using media consist of Arduino Uno, SMS Gateway, ultrasonic sensor, relay, accu (batterai), buzzer, and adapter. The design methodology did with several stages: software design, hardware design, system implementation, and system testing. The design results show the system works well for opening and locking doors via SMS Gateway, as well as alerting via SMS when the door opened forcibly.
\end{abstract}

Keywords: automatic door, ultrasonic sensor, SMS Gateway, Arduino Uno

\section{Introduction}

Technology is made to make life easier for a human to improve the quality of life[1]-[3]. Control system is a technology that is created based on the process of setting a scale so that it is in a specific range or value[4]-[7].

The implementation of a control system can implemented in the door lock automation. Various published designs related to door lock automation are: Smart House Based on SMS using Arduino Microcontroller (2013) [8], Design of Automatic Home Based on Microcontroller System (2013) [9], Security Control System for Home Based on SMS with ATMEGA 8535 Microcontroller (2013) [10], Design of Home Security System Based on SMS Gateway with Arduino ATMEGA 2560 Microcontroller (2014) [11], and Prototype of Auto Fence Based on Arduino Uno ATMEGA 328P with Fingerprint Sensor (2015) [12].

In this paper, designed a remote automatic door system using Arduino Uno. Arduino Uno serves as the processor of the door lock control via SMS Gateway. SMS Gateway is a command tool by homeowners to lock and unlock the door from anywhere. So homeowners do not have to go back home just to lock the door. This tool implemented in the door with ultrasonic sensor inserted as security when the door opened forcibly. The ultrasonic sensor will be active when the door lock is locked, and when homeowner forgets to lock the door, then Arduino Uno will give the door status information to the homeowner via SMS Gateway.

\section{Methodology}

The design methodology of door control system shown in Fig. 1.

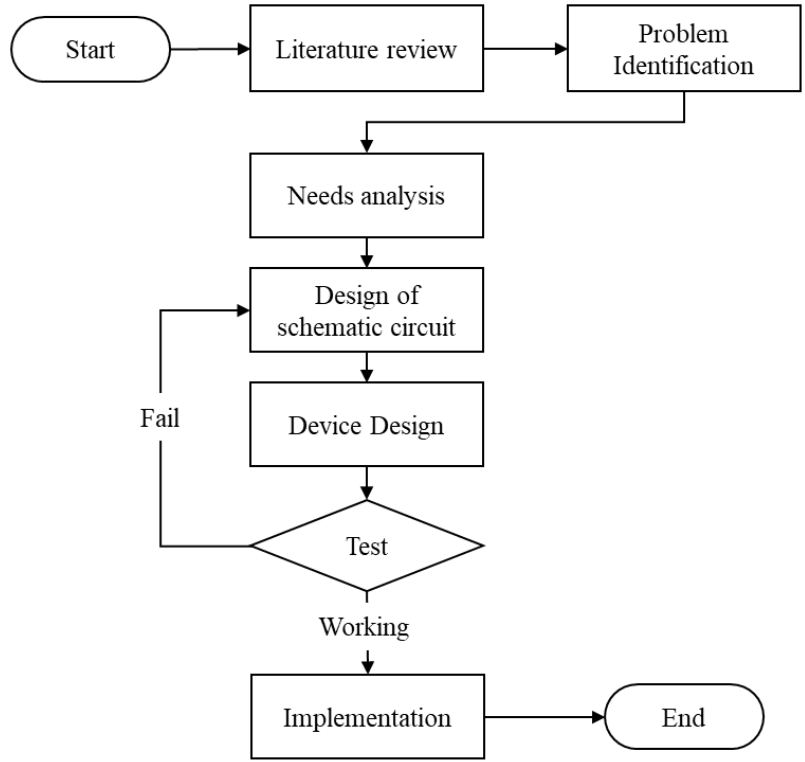

Fig. 1: Design procedure

\section{Device Design}

The design of door control system appliance uses several components, namely: Arduino Uno, SMS gateway, selenoid, ultrasonic sensor, and alarm (Fig. 2.). Fig. 2 shows the Arduino has a vital role in this system as the control center of the whole system. This system worked when there are input commands via SMS gateway and forwarded to be processed by Arduino Uno. Arduino Uno will give control to the selenoid to lock the door. Input command on SMS gateway is set such that Arduino Uno will process only specified words as an input command. 


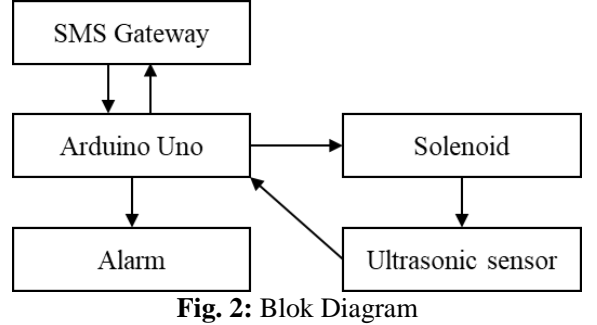

When the selenoid is in a locked state, automatically the ultrasonic sensor will be turned on. If force opens the door, then the ultrasonic sensor will read the door motion, and Arduino Uno will send a warning via SMS gateway media that there is a door indicator opened by force.

\subsection{Software Design}

In designing automatic lock system is used software by using the C language.

\subsubsection{Ultrasonic Sensor}

Ultrasonic sensors have four pins: VCC, Trigger, Echo, and Gnd. The program was made to declare that pin 8 as a trigger on the Ultrasonic sensor, and pin 7 as the ultrasonic Echo.

\subsubsection{SMS Gateway Program}

SMS gateway has two input program that is for the command at the time of giving a warning, and at the time of SMS gateway become the receiver media command. The input program created when the SMS gateway provides a signal with.

In the SMS text content program, the warnings set as desired. The time range between the first SMS alert with the next warning SMS set by changing the time delay. Calculation of delay time on Arduino Uno used a unit of 1 second. When the door is open, the SMS gateway warns.

When sending an input command to an SMS gateway, Arduino Uno will only read a specific SMS text input as a command to lock the selenoid, as well as when it will unlock the selenoid. Arduino will read only specific SMS text as an input command. Text SMS command set as desired.

\subsubsection{Solenoid Key}

The program was created to activate the selenoid key and simultaneously activate the ultrasonic sensor. When the ultrasonic sensor is active, it will give a command to the buzzer and SMS gateway to warn of any forced door opening.

\subsubsection{Program Buzzer}

Buzzer closely associated with ultrasonic sensors because when the ultrasonic sensor is active, then the buzzer is also automatically active, when ultrasonic sensors detect the object then the buzzer will light up. If the ultrasonic sensor output is more than $5 \mathrm{~cm}$, then the buzzer is not lit.

\subsection{Hardware Design}

Each pin on each module is connected to Arduino Uno, VCC, and ground. In this phase, each module: relay, ultrasonic sensor, selenoid key, SMS gateway, and buzzer connected to Arduino.

\subsubsection{Assemble Arduino with Ultrasonic Sensor}

Ultrasonic Sensor HC SR04 has four different pins in accordance with their respective functions are: VCC, Trigger, Echo and Gnd. As in Fig. 3. each pin on the ultrasonic sensor will be connected to Arduino Uno with the jumper medium.
- VCC pin on the ultrasonic sensor connected to a 5 Volt VCC pin on Arduino Uno using a red jumper.

- Pin Trigger connected to pin 8 on Arduino Uno. The function of pin Trigger is for the release of signals from the sensor.

- Echo pins connected to pin 7 on Arduino Uno. The function of Echo pin is to catch the reflected signal from the object.

- Gnd pin connected to ground, it can be input to ground on Arduino Uno directly or can be connected to another ground.

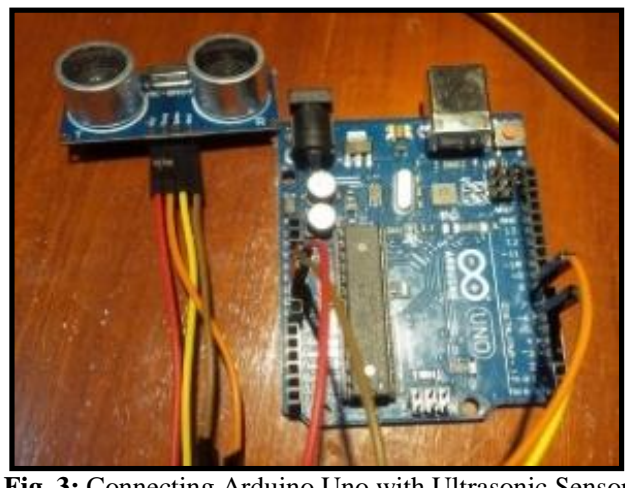

Fig. 3: Connecting Arduino Uno with Ultrasonic Sensor

\subsubsection{Assemble Arduino with Relay}

In this phase, assemble between relays with Arduino Uno. 3 pin of the relay connected to Arduino Uno, the first pin VCC connected to the 5 volt pin on Arduino pin, the In 1 pin on the relay connected to pin 13 of the Arduino Uno which serves as a command to open or close the selenoid key, pin Gnd on relay connected to pin ground on Arduino Uno (Fig. 4.). An Arduino power supply is 5 Volts obtained from the accu or from home electricity through an adapter.

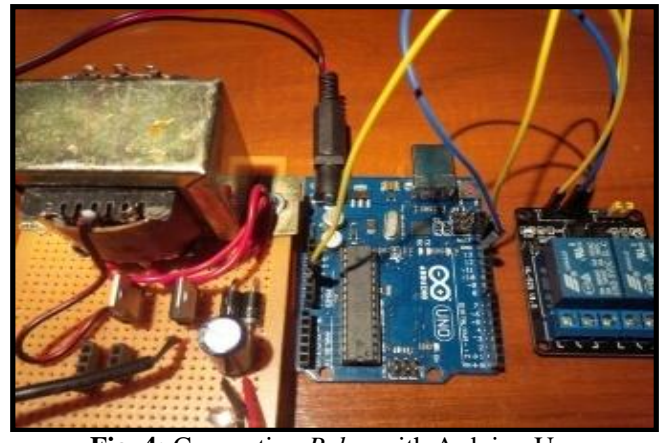

Fig. 4: Connecting Relay with Arduino Uno

\subsubsection{Assemble Arduino, Selenoid Key, and Relay}

The connected relay on the Arduino Uno receives a voltage input from the 12 volt battery and the outlet is connected to the selenoid key and the ground on the selenoid key is connected to the negative pole on the batteries (Fig. 5.).

The In 1 pin on the relay serves as a selenoid key control to open or close the door. If the command from arduino to unlock the selenoid, then the relay will provide voltage to the key coil of selenoid. Next the coil turns into a magnet and pulls the locking iron, so the selenoid key will open.

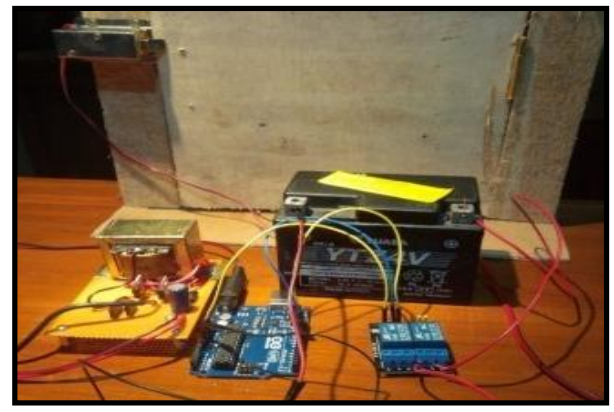

Fig. 5: Assemble Arduino, Selenoid Key, and Relay 


\subsubsection{Assemble SMS Gateway with Arduino}

There are two outputs on the adapter that is 5 volts and 9 volts. 5 Volt will be used for Arduino, while 9 Volt is used for SMS Gateway. Both pins on the SMS gateway, Tx and Rx are connected to Tx and Rx pins on Arduino Uno (Fig. 6.).

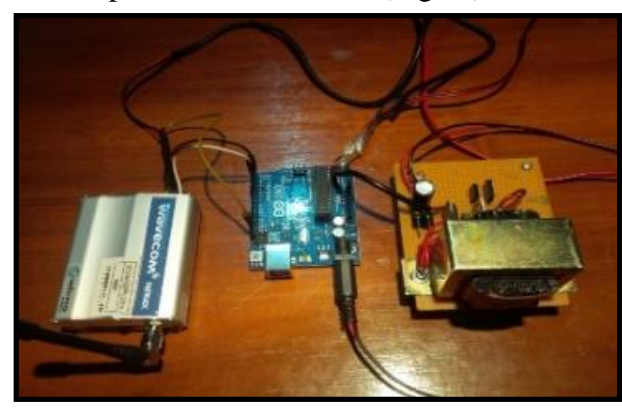

Fig. 6: Assemble SMS Gateway with Arduino

SMS gateway serves as the receiver of the command of the user system as well as the sender of a warning to the user in the form of SMS alert.

\subsubsection{Assemble Arduino with Buzzer}

Both pins on the buzeer are connected directly to Anduino, the pin VCC 5 Volt and the ground I pin (Fig. 7.). Components functioning as an additional alert works when there is an indication of theft with a marked ultrasonic sensor that detects the door open when the lock of the selenoid is locked. Similar with ultrasonic sensors, this buzzer itself will automatically activate when the lock selenoid locked.

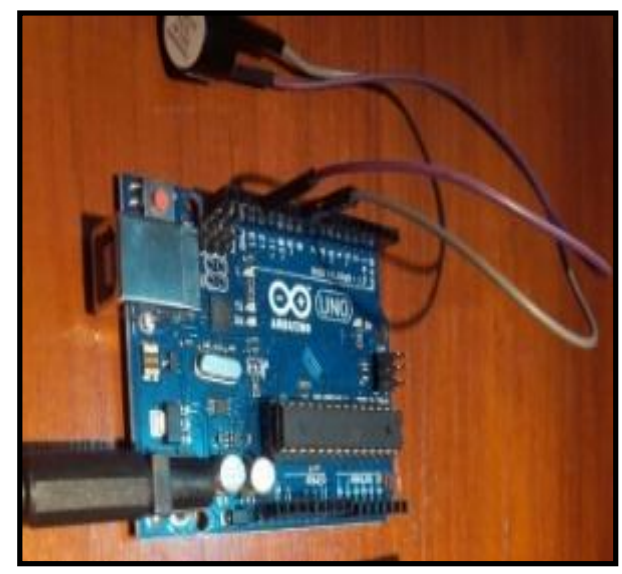

Fig. 7: Assemble Arduino with Buzzer

After all the tools are assembled, the door control system are presented in Fig. 8.

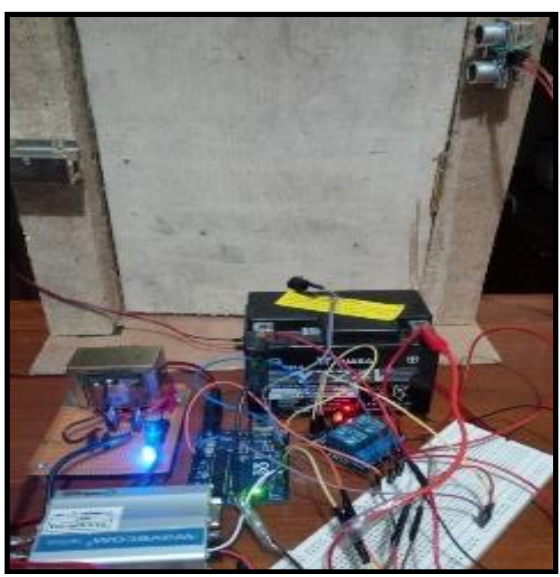

Fig. 8:Door control system

\section{Testing and Analysis}

In this phase of the system that has been completed will be tested, there are several ways of testing to be done that is testing the distance of ultrasonic sensors, SMS alert delay, and testing of the accu resilience. In this phase a pre-made tool is tested to determine whether the system is running as expected.

\subsection{Ultrasonic Sensor Testing}

The program applied the Arduino command on the Ultrasonic sensor to detect an open door of $5 \mathrm{~cm}$. At this stage testing the distance of Ultrasonic sensor to prove that the input on the program sync with reality.

Table 1: Ultrasonic Sensor Response

\begin{tabular}{|l|c|c|c|}
\hline \multirow{2}{*}{ No } & \multirow{2}{*}{ Distance (cm) } & \multicolumn{2}{|c|}{ Response } \\
\hline & & Legible & Un-legible \\
\hline 1 & 1 & $\checkmark$ & \\
\hline 2 & 2 & $\checkmark$ & \\
\hline 3 & 3 & $\checkmark$ & \\
\hline 4 & 5 & $\checkmark$ & $\checkmark$ \\
\hline 5 & 6 & & $\checkmark$ \\
\hline 6 & 7 & & $\checkmark$ \\
\hline 7 & 8 & & $\checkmark$ \\
\hline 8 & 9 & & \\
\hline 9 & 10 & & \\
\hline 10 & & & \\
\hline
\end{tabular}

Table 1 shows that with a distance of $5 \mathrm{~cm}$ then ultrasonic sensors will detect an object, if the object in front is more than $5 \mathrm{~cm}$ then it will not be detected by the ultrasonic sensor.

\subsection{Selenoid Sensor Testing}

The selenoid response test begin from sending an SMS to open or lock the door. When SMS is sent up to selenoid give response lock or unlock.

Table 2:Selenoid Response

\begin{tabular}{|c|c|c|}
\hline No & Time & Selenoid Response (second) \\
\hline 1 & $07: 00$ & 5 \\
\hline 2 & $08: 00$ & 4 \\
\hline 3 & $09: 00$ & 6 \\
\hline 4 & $10: 00$ & 5 \\
\hline 5 & $11: 00$ & 5 \\
\hline 6 & $12: 00$ & 5 \\
\hline 7 & $13: 00$ & 4 \\
\hline 8 & $14: 00$ & 4 \\
\hline 9 & $15: 00$ & 6 \\
\hline 10 & $16: 00$ & 5 \\
\hline 11 & $17: 00$ & 5 \\
\hline 12 & $18: 00$ & 4 \\
\hline 13 & $19: 00$ & 4 \\
\hline 14 & $20: 00$ & 4 \\
\hline 15 & $21: 00$ & 5 \\
\hline 16 & $22: 00$ & 4 \\
\hline 17 & $23: 00$ & 4 \\
\hline 18 & $24: 00$ & 6 \\
\hline 19 & $01: 00$ & 4 \\
\hline 20 & $02: 00$ & 5 \\
\hline 21 & $03: 00$ & 4 \\
\hline 22 & $04: 00$ & 4 \\
\hline 23 & $05: 00$ & 5 \\
\hline 24 & $06: 00$ & 24 \\
\hline
\end{tabular}

The selenoid response test is performed within 24 hours, and the response speed of selenoid when the door locks on average every hour is 4 seconds, and the slowest response is 6 seconds. 
Table 2: Selenoid Response when opening the door

\begin{tabular}{|c|c|c|c|}
\hline No & Time & $\begin{array}{c}\text { Selenoid respond } \\
\text { (second) }\end{array}$ & SMS Alert (second) \\
\hline 1 & $07: 00$ & 4 & 5 \\
\hline 2 & $08: 00$ & 5 & 4 \\
\hline 3 & $09: 00$ & 5 & 4 \\
\hline 4 & $10: 00$ & 4 & 5 \\
\hline 5 & $11: 00$ & 4 & 6 \\
\hline 6 & $12: 00$ & 5 & 7 \\
\hline 7 & $13: 00$ & 6 & 6 \\
\hline 8 & $14: 00$ & 6 & 6 \\
\hline 9 & $15: 00$ & 7 & 4 \\
\hline 10 & $16: 00$ & 4 & 5 \\
\hline 11 & $17: 00$ & 6 & 7 \\
\hline 12 & $18: 00$ & 5 & 4 \\
\hline 13 & $19: 00$ & 4 & 5 \\
\hline 14 & $20: 00$ & 5 & 6 \\
\hline 15 & $21: 00$ & 4 & 4 \\
\hline 16 & $22: 00$ & 5 & 4 \\
\hline 17 & $23: 00$ & 4 & 5 \\
\hline 18 & $24: 00$ & 5 & 3 \\
\hline 19 & $01: 00$ & 5 & 4 \\
\hline 20 & $02: 00$ & 4 & 4 \\
\hline 21 & $03: 00$ & 5 & 5 \\
\hline 22 & $04: 00$ & 4 & 4 \\
\hline 23 & $05: 00$ & 6 & 5 \\
\hline 24 & $06: 00$ & 5 & 5 \\
\hline
\end{tabular}

In testing the selenoid response time when unlocking, the average speed of selenoid response when unlocked every hour is 5 seconds. After the selenoid is open, a warning SMS is sent to a preprogrammed number, with an average SMS sending time of 4 seconds, from open selenoid to SMS received by the home owner.

Table 4: SMS allert when there's theft

\begin{tabular}{|c|c|c|}
\hline No & Time & SMS Alert (second) \\
\hline 1 & $07: 00$ & 4 \\
\hline 2 & 08:00 & 5 \\
\hline 3 & 09:00 & 6 \\
\hline 4 & $10: 00$ & 4 \\
\hline 5 & $11: 00$ & 6 \\
\hline 6 & $12: 00$ & 6 \\
\hline 7 & $13: 00$ & 4 \\
\hline 8 & $14: 00$ & 7 \\
\hline 9 & $15: 00$ & 5 \\
\hline 10 & $16: 00$ & 7 \\
\hline 11 & $17: 00$ & 6 \\
\hline 12 & $18: 00$ & 7 \\
\hline 13 & $19: 00$ & 5 \\
\hline 14 & $20: 00$ & 6 \\
\hline 15 & $21: 00$ & 5 \\
\hline 16 & $22: 00$ & 4 \\
\hline 17 & $23: 00$ & 5 \\
\hline 18 & $24: 00$ & 4 \\
\hline 19 & 01:00 & 4 \\
\hline 20 & $02: 00$ & 3 \\
\hline 21 & 03:00 & 4 \\
\hline 22 & 04:00 & 4 \\
\hline 23 & $05: 00$ & 6 \\
\hline 24 & 06:00 & 5 \\
\hline
\end{tabular}

At the SMS alert time test the average speed of the warning response when the theft occurred on average for 4 seconds, from start buzzer on until the SMS received by the owner. The buzzer will light up instantly when the ultrasonic sensor reads the door open when the lock condition of the door of the house is locked.

\subsection{Battery Durability Testing}

This test aims to determine the ability of Battery (accu) in power back-up. The required power on each component is calculated using the equation (1):

\section{$\mathbf{P}=\mathbf{V} \mathbf{x} \mathbf{I}$}

Where: $\quad \begin{aligned} \mathrm{I} & =\text { Current (Ampere) } \\ \mathrm{P} & =\text { Power }(\text { Watt })\end{aligned}$

$\mathrm{P}=$ Power $($ Watt $)$
$\mathrm{V}=$ Voltage (Volt)
The power requirements of each component are as follows:

- Selenoid key requires 4.2 Watts

- Ultrasonic sensor requires 0.1 Watt

- Buzzer requires 1.5 Watt

- SMS Gateway requires 9 Watt

- Relays require 1 Watt

Accu Specs tested is 12 V 3 Ah. At the time the system is locked, the total power is 10.6 watts, with $\mathrm{I}=3 \mathrm{Ah} / 0.883 \mathrm{~A}$, with a duration of accu time of 2,718 hoursAt the moment the lock of the selenoid is locked,accu can back-up for 2.718 hours. Further calculation is done when the key selenoid in open state, then the ability of Accu in back-up power counted for 2,029 hours.

After the accu endurance test, the batteries can last for 2 hours 30 minutes in a locked state or when the selenoid is not active. The accu endurance test is then performed in an active selenoid state, or when the unlocked home lock can last for 2 hours 5 minutes. The difference between the test results and the calculation results is influenced because the condition of batteries used.

\section{Conclusion}

The design results show the system works well for opening and locking doors via SMS Gateway, as well as alerting via SMS when the door opened forcibly. The components used are: Arduino Uno, SMS gateway, selenoid key, ultrasonic sensor, relay, accu, adapter, and buzzer.

Based on the result of work tool response analysis, it can be concluded that:

- Accu durability, when the door is locked, the batteries can back up to 2,389 hours, and when the selenoid key is open the batteries can back up to 2,029 hours.

- The average speed of selenoid response when locking the door is 4 seconds.

- The average speed of selenoid response when opening the door is 5 sec.

- The average speed of an open lock SMS alert is 4 seconds.

- The average speed of SMS alert response when there is a forced open door that is 4 seconds.

\section{References}

[1] M. A. Ramdhani, H. Aulawi, A. Ikhwana, and Y. Mauluddin, "Model of green technology adaptation in small and medium-sized tannery industry," J. Eng. Appl. Sci., vol. 12, no. 4, pp. 954-962, 2017.

[2] A. Pamoragung, K. Suryadi, and M. A. Ramdhani, "Enhancing the implementation of e-Government in indonesia through the highquality of virtual community and knowledge portal," in Proceedings of the European Conference on e-Government, ECEG, 2006, pp. 341-348.

[3] M. A. Ramdhani, D. S. Maylawati, A. S. Amin, and H. Aulawi, "Requirements Elicitation in Software Engineering," Int. J. Eng. Technol., vol. 7, no. 2.29, pp. 772-775, 2018.

[4] N. Fajrin, I. Taufik, N. Ismail, L. Kamelia, and M. A. Ramdhani, "On the Design of Watering and Lighting Control Systems for Chrysanthemum Cultivation in Greenhouse Based on Internet of Things," IOP Conf. Ser. Mater. Sci. Eng., vol. 288, no. 1, p. 012105 , 2018.

[5] L. Kamelia, M. A. Ramdhani, A. Faroqi, and V. Rifadiapriyana, "Implementation of Automation System for Humidity Monitoring and Irrigation System," IOP Conf. Ser. Mater. Sci. Eng., vol. 288, no. 1, p. 012092, 2018.

[6] E. A. Z. Hamidi, L. S. Dzudin, A. Faroqi, and M. A. Ramdhani, "The Implementation of Alert System for LAN Network Monitoring Using the Dude Based Email," IOP Conf. Ser. Mater. Sci. Eng., vol. 288, no. 1, p. 012054, 2018.

[7] H. Aliah et al., "Dye Sensitized Solar Cells (DSSC) Performance Reviewed from the Composition of Titanium Dioxide (TiO2)/Zinc Oxide (ZnO)," IOP Conf. Ser. Mater. Sci. Eng., vol. 288, no. 1, p. $012070,2018$.

[8] M. B. P. Achyat, "Rumah Pintar Berbasis Pesan Singkat dengan Menggunakan Mikrokontroler Arduino,” Institut Pertanian Bogor, Bogor, 2013. 
[9] M. A. Setiawan, "Rancang Bangun Sistem Otomatis Rumah Berbasis Mikrokontroler," Surabaya, 2013.

[10] S. Riyadi, "Sistem Pengendalian Keamanan Pintu Rumah Berbasis SMS Menggunakan Mikrokontroler ATMEGA 8535," Indones. J. Netw. Secur., vol. 2, no. 4, pp. 7-11, 2013.

[11] S. Purnomo, "Perancangan Sistem Keamanan Rumah menggunakan SMS Gateway Menggunakan Mikrokontroler Arduino ATMEGA 2560," Tanjungpinang, 2014.

[12] Y. El Anwar, N. Soedjarwanto, and A. S. Repelianto, "Prototype Penggerak Pintu Pagar Otomatis Berbasis Arduino Uno ATMEGA 328P dengan Sensor Sidik Jari,” Electrician, vol. 9, no. 1, pp. 30-41, 2015 